\title{
Neuroanatomia do medo em mamíferos
}

\section{Neuroanatomy of fear in mammals}

\author{
Beatriz Gneiding ${ }^{1 *}$, José Eduardo Basilio Oliveira Gneiding ${ }^{1,2}$, Joelma Lucioli ${ }^{2}$, Daniela Romani Bonotto ${ }^{1}$, \\ Bruna Carvalho da Silva ${ }^{2}$, Carlos Jose Gomes ${ }^{1}$ \\ ${ }^{1}$ Pontifícia Universidade Católica do Paraná (PUCPR), Curitiba, PR, Brasil \\ ${ }^{2}$ Universidade Regional de Blumenau (FURB), Blumenau, SC, Brasil
}

\section{Resumo}

No transcorrer da história, pensadores e cientistas buscaram compreender as emoções, o comportamento e sua ligação com estruturas cerebrais e funções fisiológicas. Apesar da complexidade do encéfalo nas diferentes espécies, algumas ações cerebrais são comuns a todos os mamíferos, como as ocasionadas pelo medo. Este foi detalhadamente mapeado, evidenciando a existência de circuitos neurais específicos para o comportamento emocional. 0 medo possui dois circuitos distintos, um para o estímulo condicionado e outro para o incondicionado. 0 medo condicionado, também conhecido como medo aprendido, é desencadeado por estímulos que antecipam acontecimentos aversivos previamente vivenciados pelo animal, através de adaptações ou situações no ambiente no qual está estabelecido. Já o medo incondicionado, não derivado de experiências vividas anteriormente, conduz para o comportamento de fuga e/ ou ataque na presença de um perigo real existente, a fim de livrar-se de uma situação ameaçadora. Embora as mesmas estruturas neurais estejam envolvidas, as vias utilizadas nesse mecanismo são distintas. Estes tópicos são abordados mais detalhadamente nesta revisão bibliográfica.

Palavras-chave: Neuroanatomia. Medo. Sistema límbico. Amígdala. Emoções. Comportamento.

\section{Abstract}

In the course of history, thinkers and scientists have tried to understand emotions, behavior, and their connection to brain structures and physiological functions. Despite the complexity of the encephalon in different species, some brain actions are common to all mammals, such as those caused by fear. This was detailed mapped, evidencing the existence of specific neural circuits for emotional behavior. Fear has two distinct circuits, one for the conditioned stimulus and another for the unconditioned. Conditioned fear, also known as learned fear, is triggered by stimuli that anticipate aversive events previously experienced by the animal, through adaptations or situations in the environment in which it is established. Unconditioned fear, not derived from experiences previously experienced, leads to escape and/or attack behavior in the presence of a real danger in order to get rid of a threatening situation. Although the same neural structures are involved, the pathways used in this mechanism are distinct. These topics are covered in more detail in this literature review.

Keywords: Neuroanatomy. Fear. Limbic system. Amygdala. Emotions. Behavior. 


\section{Introdução}

Presente na vida de todos os mamíferos, o medo permanece sendo importante no processo de seleção natural, assumindo um papel fundamental na sobrevivência (Goleman, 2011). Influenciado por diversos fatores como a interação de genes com o ambiente e o comportamento, o medo possui um processo anatomofisiológico basicamente igual em todos os mamíferos (Kandel et al., 1997).

Tais descobertas resultaram de diversos estudos científicos e filosóficos no decorrer da história, onde se buscou conhecer as bases do comportamento e das emoções. Para a obtenção de tais resultados, focouse principalmente nas vias do medo, que apesar de ser uma emoção subjetiva, seria a mais aceitável para comparação entre as diversas espécies animais (Kandel et al., 1997; Esperidião-Antonio, 2008).

0 ramo da neurociência se encontra em constante desenvolvimento. Estudos sobre o cérebro permitem a compreensão dos distúrbios emocionais, bem como possíveis formas de solucioná-los. Objetivouse com este trabalho conhecer os circuitos do medo e os estímulos que levam ao seu desencadeamento.

\section{Pensadores, neurociência e o medo}

O desenvolvimento do que conhecemos por cérebro hoje se iniciou há 700 milhões de anos com o surgimento do primeiro neurônio, e estima-se que o primeiro encéfalo tenha se desenvolvido há 250 milhões de anos. As adaptações, entretanto, são constantes e a complexidade deste órgão não deixou de progredir. 0 cérebro dos mamíferos como o conhecemos surgiu há aproximadamente $150 \mathrm{mil}$ anos. Desta forma, os mistérios do encéfalo, mente e comportamento sempre instigaram cientistas e pensadores. Linhas de raciocínio foram criadas e, dentre elas, Aristóteles propôs o mentalismo, Descartes o dualismo e Darwin o materialismo (Kolb e Whishaw, 2002). A partir destas, outros estudiosos propuseram novas teorias que explicassem a associação entre as estruturas anatômicas, suas funções fisiológicas e a reação expressa com o comportamento dos indivíduos.

A confirmação do desenvolvimento cerebral pode ser considerada pelas emoções, pois com a derivação deste órgão, estas tornaram-se mais sutis. Apesar de sua subjetividade, algumas definições tentam exprimir seu significado. Zacharias e Zacharias (1991) a definem como um estado transitório de excitação mental, alterações de consciência, mudanças comportamentais e fisiológicas, além de distúrbios funcionais físicos. Teillery (2017) afirma que estímulos podem provocar uma reação emocional, consequência das representações mentais geradas pelo indivíduo, produzindo subsequentemente manifestações corporais. Brandão (2012) a define como sendo fenômenos psicomotores, usualmente associada a distúrbios neurovegetativos gerados por algum estímulo externo. Kandel et al. (1997) dizem que deve haver participação de algum componente cognitivo, onde o córtex cerebral deva estar envolvido, mas que as áreas subcorticais do sistema nervoso (tronco cerebral, hipotálamo e amígdala) são responsáveis pelas respostas endócrinas, autônomas e motoras associadas às emoções; no caso do medo, taquicardia, taquipneia, hipossalivação, sudorese e tensão muscular.

Algumas hipóteses foram propostas desde o século XIV na busca pela compreensão da origem do medo. O psicólogo e filósofo Willian James (1884) e o médico Carl Lange (1922) propuseram que um estímulo pode ocasionar alterações fisiometabólicas, mas que as sensações geradas por ele podem ser definidas como emoção. Considerando que um estímulo emocional é capaz de promover transtornos autonômicos, vivenciar o medo é perceber essas alterações, sendo o medo, de acordo com os autores, derivado do tremor e não o contrário, onde mudanças fisiológicas seriam antecessoras às emoções (Cannon, 1931; Kandel et al. 1997; Deak, 2011; Brandão, 2012; Damasio e Carvalho, 2013). A atribuição destas respostas ao comportamento emocional apenas em nível somático deixa de ponderar acerca de fatores anatômicos e fisiológicos extremamente relevantes, como a influência do tálamo. Desta forma, as emoções não existem sem manifestações fisiológicas e comportamentais, e a experiência emocional subjetiva seria na verdade causada por elas (Cannon, 1931; Lent, 2010).

A teoria proposta por Walter Cannon (1927) e Philip Bard (1934 a,b) sugere que estruturas subcorticais do sistema nervoso central geram 
a subjetividade emocional, bem como as reações fisiológicas e comportamentais, supondo que as emoções produzidas pelo hipotálamo sofram supressão do tálamo e do córtex. Em experimento com gatos, esses autores observaram que a a remoção do córtex permitia respostas emocionais, entretanto com a excisão do hipotálamo, estas respostas deixavam de existir. Esta teoria defende que as emoções seriam estruturadas no tálamo e expressas ao nível do hipotálamo, onde a região do tálamo seria um "centro de coordenação" das emoções, podendo ou não haver experienciação das mesmas de acordo com a integridade do córtex, mas que desencadearia atividades musculares e viscerais de qualquer modo. Sua importância foi atribuída ao fato de a elaboração de processos emocionais ser desencadeada por mecanismos diencefálicos (Cannon, 1931; Kandel et al. 1997; LeDoux, 2003; Lent, 2010; Brandão, 2012).

A teoria de Papez (1937) sugeriu que os componentes do lobo límbico seriam a base neural das emoções. Desta forma, alterou-se a perspectiva de que existiriam centros de coordenação emocional e passou-se a considerar um sistema que ordenasse as emoções, onde diversas regiões estariam interligadas atuando em diferentes elementos das emoções. Surgiu, desta forma, o chamado circuito de Papez, posteriormente denominado de sistema límbico, que está diretamente ligado a comportamentos emocionais, principalmente os relacionados à preservação da espécie e à autopreservação, sendo filogeneticamente a parte mais antiga do córtex cerebral (Kandel et al., 1997; Romero, 2000; Lent, 2010; Brandão, 2012; Damasio e Carvalho, 2013).

Em relação à preservação da espécie, o medo desempenha um importante papel e pode ser considerado como emoção e, também, como comportamento, sendo caracterizado por qualquer reação instintiva com o objetivo de preservar o indivíduo ou a espécie (Oliveira, 2000). A origem semântica da palavra medo é oriunda do latim metus. Zacharias e Zacharias (1991) a definem como uma reação do indivíduo quando em situação de perigo, podendo a ameaça ser ambiental ou somática. Para Pinel (2005), é a resposta gerada pela ameaça ou por sua expectativa.

0 medo, portanto, vem acompanhando os seres no decorrer da evolução e está sendo estudado há muitos anos por diversos cientistas. Algumas ações cerebrais são comuns a todos os mamíferos, como as ocasionadas pelo medo, que é gerado por estímulos que dão início à conexão entre as regiões neurais envolvidas e os sistemas sensoriais (Kandel et al., 1997; Esperidião-Antonio, 2008).

\section{Sistema nervoso}

O sistema nervoso ( $\mathrm{SN}$ ) se divide topograficamente em sistema nervoso central (SNC) e sistema nervoso periférico (SNP). O SNC é composto pela medula espinhal e encéfalo, que compreende bulbo, ponte, mesencéfalo, cerebelo, diencéfalo e telencéfalo. O SNP se divide em nervos (espinhais e cranianos), gânglios e terminações nervosas (König et al., 2004; Machado, 2006). Foi no ser humano que houve o ápice da encefalização no decorrer da filogênese (Machado, 2006), entretanto existem diferenças morfológicas de peso, tamanho e volume cerebral (Br-vo $\mathrm{cm}^{3}$ ) entre as espécies de mamíferos (Haug, 1987; Chittka e Niven, 2009; Kass, 2013) (Figura 1).

As células nervosas em sua maioria são multipolares, embora possam ser bipolares ou pseudounipolares (Figura 2). As células nervosas denominadas neurônios possuem propriedades que as diferenciam das demais, como a condução de sinais bioelétricos e a capacidade de efetuar conexões com outras células nervosas, musculares e glandulares (Brandão, 2004; Herrmann e Broihier, 2018).

Existem três tipos fundamentais de neurônios no sistema nervoso: aferente, eferente e de associação. 0 aferente (sensorial) recebe estímulos do meio externo ou do próprio organismo. 0 eferente (motor) tem como função conduzir o impulso nervoso ao órgão efetor (músculo ou glândula) (Machado, 2006; Arruda, 2011a). Já o de associação ou interneurônio possui a função de coordenar complexas funções autônomas no SNC, formando circuitos complexos e fazendo conexões entre regiões distantes (Arruda, 2011a). Possuem grande relevância, pois o seu aparecimento elevou a quantidade de sinapses, tornando o SN mais complexo e permitindo a manifestação de comportamentos ainda mais específicos (Machado, 2006). 


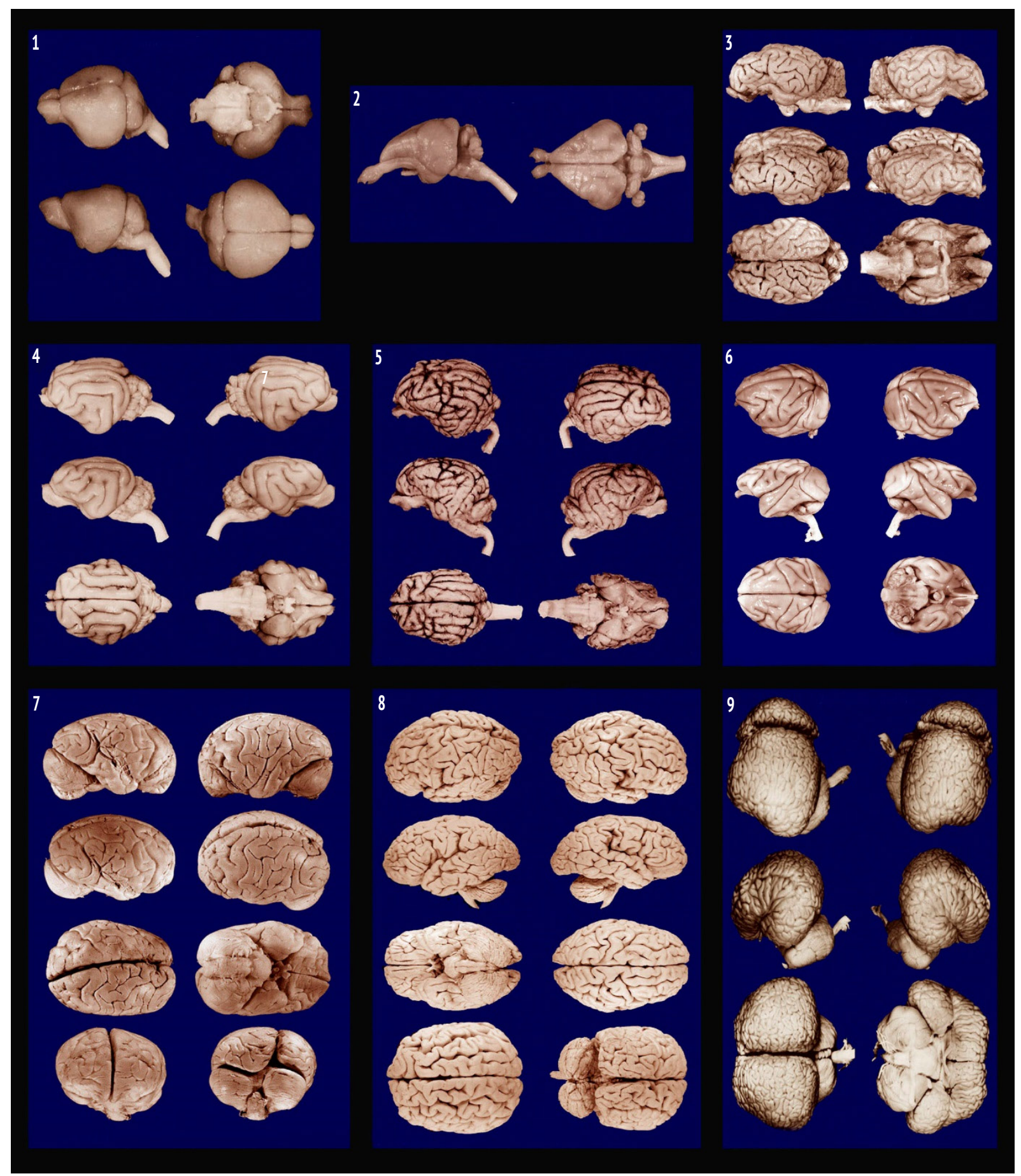

Nota: Modificado de Neuroscience Library (2018).

Figura 1 - Cérebros com diferentes morfologias, tamanhos e volume $\left(\mathrm{Br}-\mathrm{vo}_{\mathrm{cm}}^{3}\right)$ de algumas espécies de mamíferos. 1 - Camundongo (Mus musculus - Br-vo 0,3). 2 - Coelho-bravo (Oryctolagus cuniculus Br-vo 11,2). 3 - Ovelha doméstica (Ovis aries Br-vo 140). 4 - Gato doméstico (Felis catus Br-vo 28,7). 5 - Cão doméstico (Canis familiaris Br-vo 63,7). 6 - Macaco Rhesus (Macaca mulatta Br-vo 88). 7 - Gorila (Gorilla gorilla Br-vo 429). 8 - Homen (Homo sapiens Br-vo 1300). 9 - Golfinho-roaz (Tursiops truncatus Br-vo 1345). 


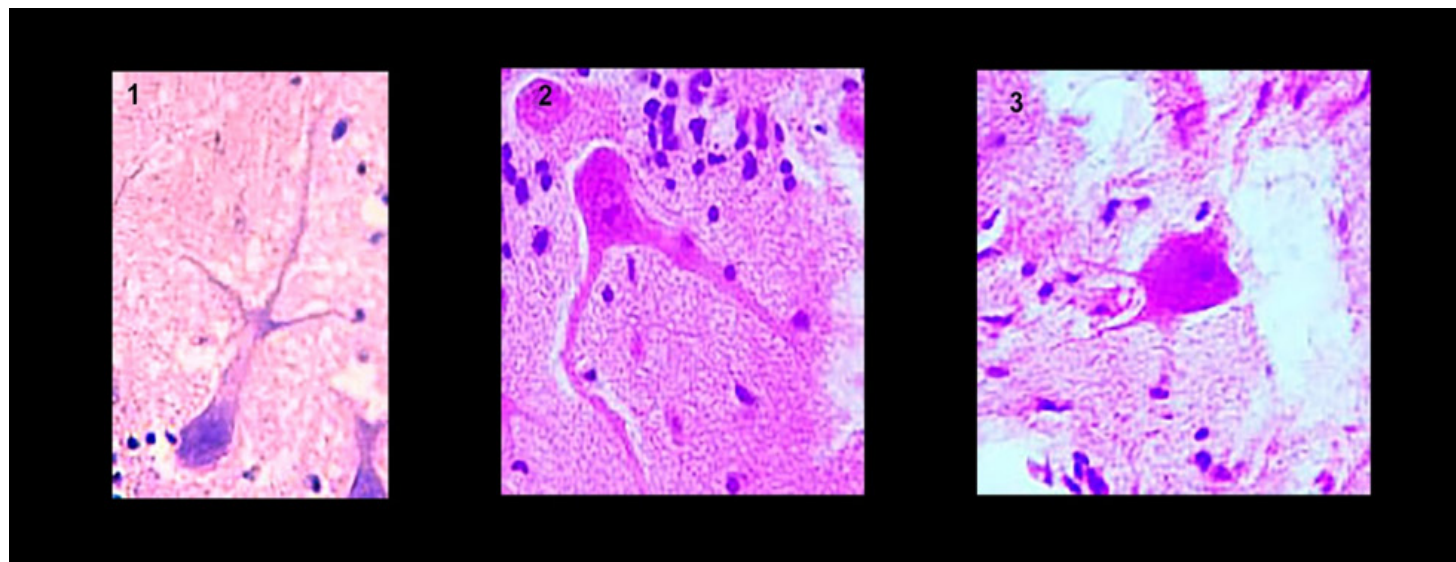

Fonte: Autores.

Figura 2 - Células nervosas (neurônios) de cão doméstico (Canis familiaris). 1 - Neurônio pseudounipolar (cerebelo). 2 - Neurônio bipolar (cerebelo). 3 - Neurônio multipolar (tronco encefálico).

\section{Sistema límbico}

A integração estrutural e funcional do diencéfalo, telencéfalo e mesencéfalo (Meneses, 2011) constitui o sistema límbico (SL), considerado o principal componente do comportamento emocional (Sánchez-Ramírez e Uribe-Velásquez, 2009; Arruda, 2011b; Meneses 2011; Damasio e Carvalho, 2013). O lobo límbico é filogeneticamente basal, está presente em todos os vertebrados (Machado, 2006), foi a primeira região a se desenvolver no cérebro e mesmo com o envolvimento do tronco encefálico por novas estruturas, manteve seu arranjo e suas funções, sendo, desta forma, considerado um córtex primitivo (Schmidt, 1979; Kolb e Whishaw, 2002; Machado, 2006; Arruda, 2011b; Cosenza, 2012; Damasio e Carvalho, 2013).

A subdivisão do sistema límbico diverge de acordo com cada autor, porém serão descritas aqui as principais estruturas envolvidas (Figuras 3 e 4).

Amígdala - Estrutura de grande relevância para o sistema límbico, possui funções referentes às emoções e expressões de comportamentos como o de luta ou fuga. Possui vários núcleos, subdivididos em três partes: área corti-comedial, que se conecta com o hipotálamo, bulbo e córtex olfativo, e que está relacionada com o feedback emocional; área basolateral, que se relaciona com o córtex pré-frontal medial e orbital, sendo este o alvo principal das entradas sensoriais, advindas do tálamo e do córtex; área central, que se interliga com o tronco encefálico, com o hipotálamo (onde mantém extensas conexões) e também com estruturas viscerais. 0 núcleo central origina a via amigdalofugal e estria terminal. Quanto à sua localização, a amígdala se encontra na porção medial do encéfalo, limitando-se com o hipocampo (Kandel et al., 1997; Oliveira, 1999; Purves, 2005; Arruda, 2011b; Cosenza, 2012; Martin, 2013; Guyton e Hall, 2017; Hall, 2017).

Área septal - Esta estrutura abrange boa parte dos núcleos septais, denominados dorsal, lateral, medial, núcleo do leito da estria terminal e núcleo do leito da comissura anterior. Anatomicamente, encontra-se abaixo do rostro do corpo caloso e está vinculada a sensações de satisfação como, por exemplo, fome, sede e desejo sexual (Machado, 2006; Arruda, 2011b; Meneses, 2011; Prada 2014).

Corpo caloso - Sua finalidade é unir os dois hemisférios cerebrais através dos axônios, formando uma comissura. Localiza-se na fissura longitudinal e se alonga para seu interior. Suas fibras se propagam formando a radiação do corpo caloso (Colaço et al., 2003; Brandão, 2012).

Córtex orbitofrontal - Apresenta maior desenvolvimento nos primatas. Acredita-se que os estados emocionais gerados em especial pela amígdala passam a ser conscientizados pelo 
córtex orbitofrontal, que é encarregado de acolher os dados de todas as propriedades sensoriais, e é responsável pelo aprendizado emocional e motivacional dos estímulos. Esta estrutura forma a base do lobo frontal, além de integrar o cérebro pré-frontal (Kolb e Whishaw, 2002; Gazzaniga et al, 2006; Deak, 2011; Martin, 2013).

Giro do Cíngulo - Une-se ao giro para-hipocampal através do istmo do giro do cíngulo, e circunda o corpo caloso. Recebe impulsos nervosos do hipotálamo e hipocampo. É considerado mesocórtex e mantém conexões com tálamo, hipocampo e amígdala (Machado, 2006; Cosenza, 2012; Prada, 2014).

Giro Para-hipocampal - É composto basicamente pelo paleocórtex e divide-se pelo giro occipitotemporal pelo sulco colateral. Encontra-se abaixo do lobo temporal, categorizado como sendo mesocórtex. É responsável por integrar os impulsos olfativos (Machado, 2006; Arruda, 2011b; Cosenza, 2012; Prada 2014).

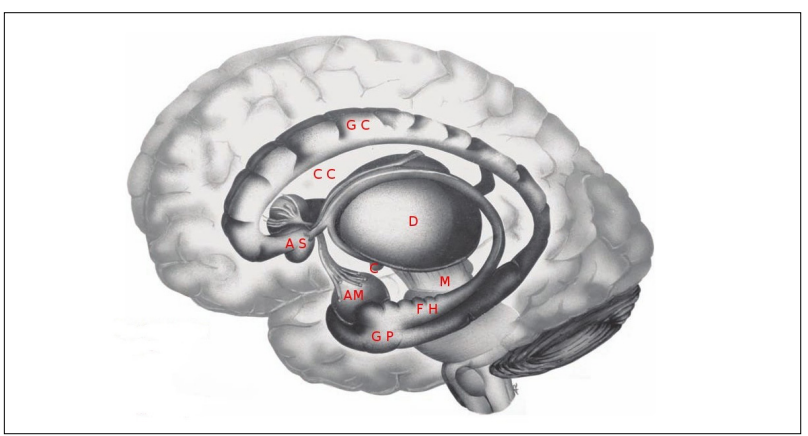

Nota: GC - Giro do cíngulo. CC - Corpo caloso. AS - Área septal. D - Diencéfalo (compreende o tálamo e hipotálamo). AM - Amigdala. C - Corpo mamilar. M - Mesencéfalo. FH - Formação hipocampal. GP - Giro parahipocampal. Modificado de Hendelman (2006).

Figura 3 - Esquema demonstrativo do lobo límbico,apresentando as principais estruturas envolvidas.

Hipocampo - Associado ao armazenamento de memória, é considerada uma estrutura primitiva do cérebro, onde o arquipálio, no decorrer da evolução, dobrou-se em si mesmo. Possui três camadas celulares, sendo, desta forma, classificado como alocórtex. Limita-se com a amígdala e se localiza na região medial ao lobo temporal (Kandel et al., 1997; Oliveira, 1999; Cosenza, 2012; Prada, 2014).

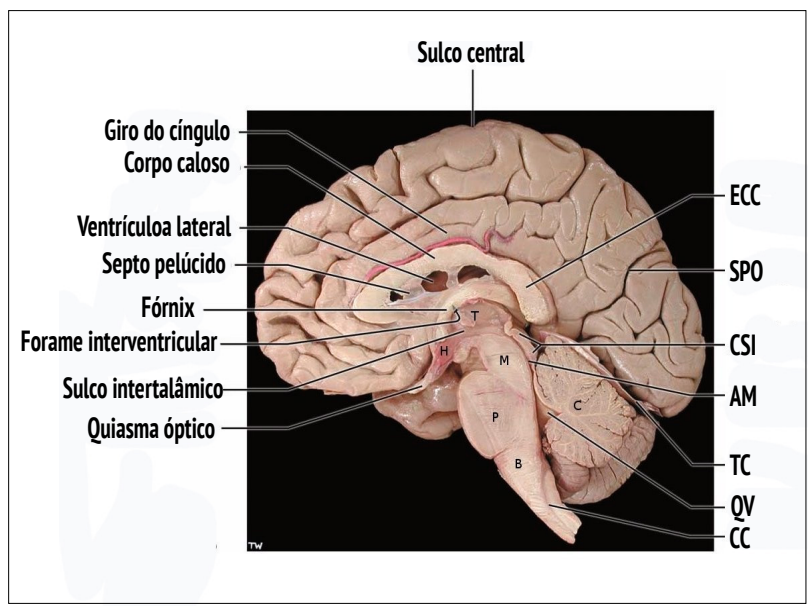

Nota: ECC - Esplênio do corpo caloso. SPO - Sulco parieto-occipital. CSI Colículo superior e inferior. AM - Aqueduto do mesencéfalo. TC - Tentório cerebelar. QV - Quatro ventrículo. CC - Canal central. Tálamo (T), hipotálamo $(H)$, mesencéfalo $(M)$, ponte $(P)$, bulbo $(B)$, cerebelo $(C)$. Modificado de Hendelman (2006).

Figura 4 - Corte sagital mostrando o encéfalo e as principais partes do sistema límbico.

Hipotálamo - É encarregado pelo controle de liberação de hormônios endócrinos e, também, de funções básicas como sede, apetite, balanço hídrico e eletrolítico. Realiza a manutenção do ciclo sonovigília, regula a temperatura e outras respostas que envolvam o comportamento. O hipotálamo é uma das mais importantes estruturas do sistema límbico e pode ser fragmentado em quatro regiões: anterior, medial, posterior e lateral. A primeira comporta os núcleos pré-óptico, supra-óptico e paraventricular; a segunda, os núcleos ventromedial, dorsomedial, arqueado, tuberal e periventricular; a terceira, os núcleos posteriores e mamilares; e, por fim, a quarta região comporta o núcleo hipotalâmico lateral, acaudilhando, desta forma, o sistema nervoso autônomo (Marcondes, 2008; Brandão, 2012; Cosenza, 2012; Martin, 2013; Nelson e Couto, 2015; Guyton e Hall, 2017).

Tálamo - Considerado um centro de associação e retransmissão com o tronco encefálico, o tálamo é um constituinte do diencéfalo. Formado por substância cinzenta que comporta múltiplos núcleos (sensoriais, motores e emocionais), estes se segmentam em cinco: anterior, posterior, lateral, 
mediano e medial. Essas estruturas possuem a função de se comunicar com o córtex, transportando as informações dos hemisférios cerebrais. 0 tálamo possui funções moduladoras, que selecionam as informações adequadas a serem processadas pelo córtex (Machado, 2006; Lent, 2010; Meneses, 2011; Brandão, 2012; Pawlowski et al., 2013).

\section{Circuitos do medo}

O medo desempenha a função de proteger o indivíduo de situações que ofereçam riscos e é comum a toda filogenia animal, embora sua expressão entre as espécies seja diferente. Assim, sabe-se que estruturas neuroanatômicas como hipotálamo, amígdala e córtex pré-frontal, além de neurotransmissores e seus receptores, estão envolvidos no medo (Kalin, 2002; Mezzasalma et al., 2004; Sánchez-Ramírez e Uribe-Velásquez, 2009).

Devido às ligações existentes entre a amígdala e o córtex cerebral, admite-se que as projeções da amígadala permitem a percepção e sofrimento do medo e outras reações emocionais. Esse processo todo é possível porque as informações recebidas pela amígdala proporcionam uma instantânea reação nas situações que oferecem perigo (Mezzasalma et al., 2004; Esperidião-Antonio, 2008).

A amígdala possui uma via principal de entrada, os núcleos basolaterais, que se encarregam de receber informações sensoriais e auditivas. 0 desencadeamento do medo se deve à conexão existente entre hipotálamo, via amigdalofugal ventral e estria terminal. Existem indícios de que há determinados tipos de circuitos neurais para o comportamento emocional baseados no estímulo que o indivíduo está sofrendo (Brandão et al., 2003; Esperidião-Antonio, 2008; Panksepp et al., 2011).

No caso do medo, há dois estímulos (condicionado e incondicionado) e a amígdala é fundamental entre estes dois sistemas (Brandão et al., 2003).

\section{Medo incondicionado}

Também conhecido como medo inato, é caracterizado por dirigir sua resposta para a fuga ou ataque a fim de se livrar de uma situação ameaçadora. Quanto ao seu circuito, a comunicação entre a via amigdalofugal e o hipotálamo são responsáveis por desencadear o medo, e o acesso direto do tálamo para a amígadala gera uma resposta mais rápida para uma possível situação de perigo (Foa e Kozak, 1986; Canteras, 2003; Esperidião-Antonio, 2008; Lent, 2010; Brandão, 2012).

Neuroanatomicamente, as estruturas envolvidas na resposta incondicionada, também denominadas de sistema cerebral aversivo, são o complexo basolateral da amígdala, a substância cinzenta periaquedutal dorsolateral (responsável pelo comportamento de fuga) e o hipotálamo medial. Estudos utilizando roedores mostraram que alguns tipos de reações como escape, ameaça defensiva, congelamento motor, ataque defensivo e avaliação de risco são similares em todos os mamíferos (Brandão et al, 2003; Canteras, 2003; Vianna e Brandão, 2003; Sánchez-Ramírez e Uribe-Velásquez, 2009). Pesquisas que submeteram roedores a odores característicos de seus predadores evidenciaram que esses animais apresentaram uma resposta mais acentuada ao medo inato quando comparado ao medo aprendido (Rosen et al., 2008).

\section{Medo condicionado}

Este medo, conhecido também como medo aprendido,édesencadeado porestímulosque indicam previamente eventos ameaçadores. 0 indivíduo passa a responder a situações desconfortáveis como frustração, punições e novas condições vinculadas à recompensa ou supressão; desse modo, o animal se adapta fisiologicamente às condições do meio em que está inserido (Brandão et al., 2003; Macrì et al., 2007; Esperidião-Antonio et al, 2008).

Graeff (2007) afirma que o termo medo condicionado não é apropriado, pois esta expressão se relaciona a uma situação ameaçadora real em que o indivíduo busca formas de se proteger. Desse modo, o autor sugeriu o termo "ansiedade antecipatória", sendo necessário haver uma situação em que o indivíduo vivencie o conflito entre a aproximação e o evitamento.

Em trabalho com animais de laboratório onde são aplicados choques elétricos juntamente com ruídos a fim de condicionar o medo, após a exposição dos animais a essa situação por algumas vezes é comum que estes respondam involuntariamente apenas 
ao ruído, sem a aplicação do choque. Nota-se, assim, uma resposta aprendida para um estímulo condicionado (LeDoux, 2002) (Figura 5).

Estudos demostram a ação do núcleo central da amígdala como a estrutura que dispõe as respostas de medo condicionado. As vias envolvidas transportam informações do tálamo para o núcleo lateral da amígdala, posteriormente transmitidas para o núcleo central (Figura 4). 0 complexo basolateral é responsável por interceder o medo condicionado na substância cinzenta periaquedutal ventral, que por sua vez desencadeia as respostas comportamentais. Estudos em animais com lesão neste complexo apresentaram o impedimento do condicionamento do medo, corroborando com a teoria apresentada. O núcleo central da amígdala se comunica com o hipotálamo e com a substância cinzenta periaquedutal no tronco encefálico, promovendo as respostas motoras somáticas. Lesões neste núcleo demonstraram prejuízo no desencadeamento de respostas ao medo condicionado; já lesões na área da substância cinzenta periaquedutal mostraram interferência na reação de congelamento (LeDoux et al., 1988; Davis, 1992; Kim et al., 1993; Kandel et al., 1997; LeDoux, 2002, 2003; Brandão et al., 2003; Canteras, 2003; Esperidião-Antonio, 2008; Sánchez-Ramírez e Uribe-Velásquez, 2009; Cosenza, 2012).

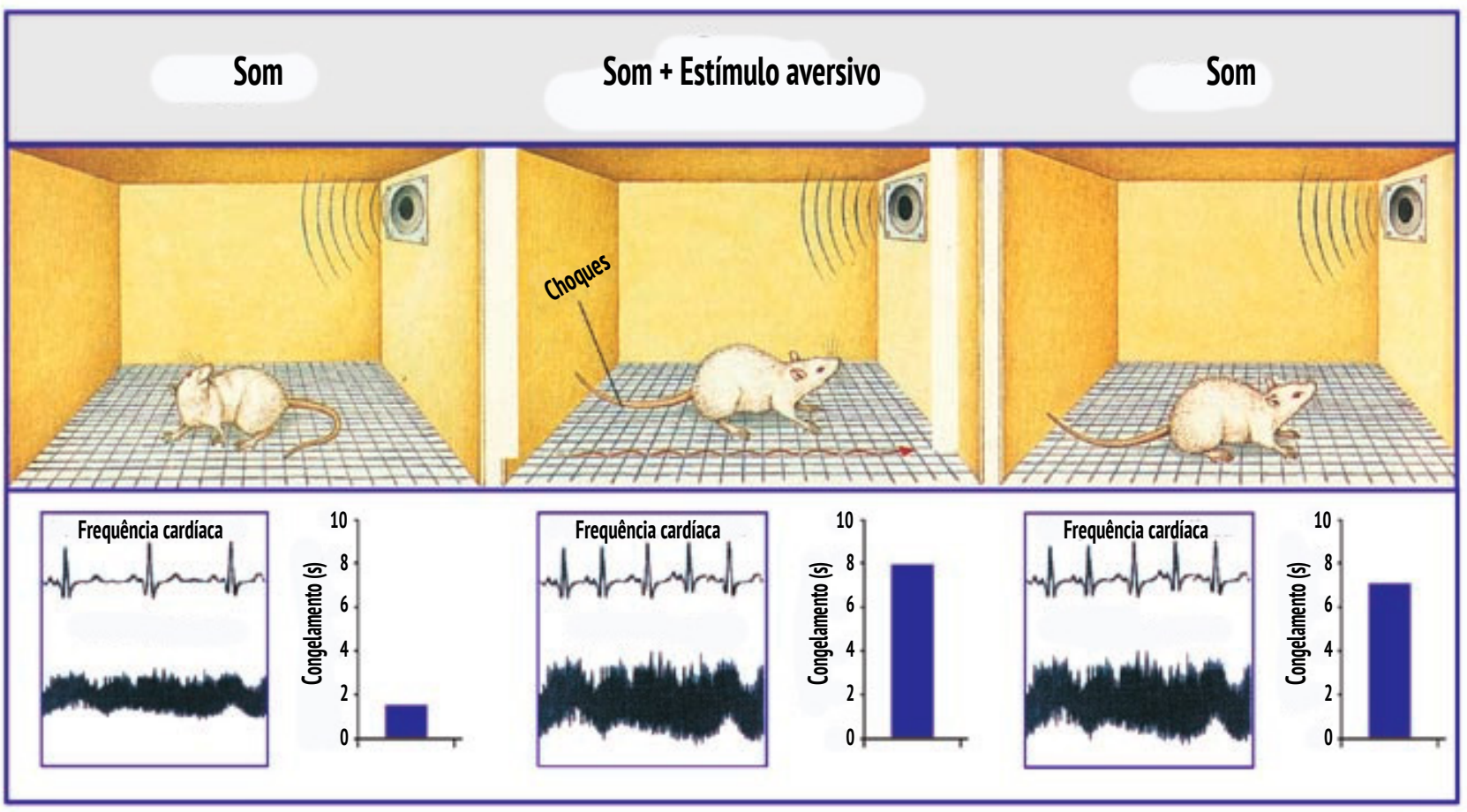

Nota: Inicialmente 0 animal é exposto apenas ao ruído. Posteriormente, juntamente ao som, adiciona-se o choque. Desta forma, quando for novamente submetido apenas ao ruído, ocorrerá uma resposta condicionada ao estímulo. Imagem de Brandão (2004).

Figura 5 - Esquema representativo da resposta condicionada.

\section{Conclusão}

A subjetividade das emoções foi um entrave por um tempo na história. Darwin já estudava este assunto em 1872 e fez relatos em seu livro "A expressão das emoções no homem e nos animais".
Posteriormente, outros cientistas buscaram respostas e novas teorias para explicar o comportamento, fundamentando-as em estruturas anatômicas e funções fisiológicas. Com estas pesquisas, perceberam que dentre os mamíferos, o Homo sapiens teve o maior desenvolvimento encefálico, 
embora uma característica comum a todos os vertebrados seja a presença do lobo límbico, considerado a parte mais basal do cérebro. Suas estruturas se integram estrutural e funcionalmente, formando um circuito responsável pelas emoções e pelo comportamento: o sistema límbico.

0 medo, definido como emoção e também como comportamento, fundamental para a sobrevivência e evolução das espécies, foi detalhadamente estudado para que a experienciação de uma situação de medo pudesse ser compreendida e mensurada. Desta forma, constatou-se que o comportamento emocional têm circuitos neurais específicos dependendo do estímulo a que se expõe o indivíduo. No caso do medo, os estímulos condicionado e incondicionado apresentam circuitos neurais distintos, e a amígdala atua como uma interface importante entre estes sistemas. Além dela, diretamente relacionados ao medo estão o hipotálamo, o córtex orbitofrontal e a substância cinzenta periaquedutal. Apesar desta relação, as vias pelas quais ocorrem são diferentes dependendo do estímulo.

Por possuirem vias distintas, podem não ser classificadas ou consideradas a mesma emoçãocomportamento, como propôs Graeff (2007), utilizando o termo "ansiedade antecipatória" em detrimento de "medo condicionado", termo usualmente aplicado. Para o autor, o medo está atrelado a uma situação de perigo real onde a ameaça esteja presente.

0 medo incondicionado, portanto, tem suas vias próprias e suas reações direcionam para fuga e/ ou ataque diante de um perigo real, e a expressão comportamental ocorre de maneira similar em todos os mamíferos. Já o medo condicionado, que também pode ser considerado um medo aprendido, é causado por estímulos que avisam antecipadamente a suposta ocorrência de uma nova situação de ameaça ou punição, o que gera uma situação de ansiedade entre o estímulo neutro e o aversivo.

\section{Referências}

Arruda WO. O Neurônio e o Tecido Nervoso. In: Meneses MS (Org.). Neuroanatomia Aplicada. Rio de Janeiro: Guanabara Koogan; 2011a. p. 2-26.
Arruda WO. Sistema Límbico. In: Meneses MS (Org.). Neuroanatomia Aplicada. Rio de Janeiro: Guanabara Koogan; 2011b. p. 260-80.

Bard P. On emotional expression after decortication with some remarks on certain theoretical views: Part I. Psychol Rev. 1934a;41(4):309-29.

Bard P. On emotional expression after decortication with some remarks on certain theoretical views: Part II. Psychol Rev . 1934b;41(5):424-49.

Brandão ML, Vianna DM, Masson S, Santos J. Organização neural de diferentes tipos de medo e suas implicações na ansiedade. Rev Bras Psiquiatr. 2003;25(Supl 2):36-41.

Brandão ML. As bases biológicas do comportamento: introdução à neurociência. São Paulo: EPU; 2004. 223 p.

Brandão ML. Psicofisiologia. São Paulo: Atheneu; 2012. 272 p.

Cannon WB. The James-Lange theory of emotions: A critical examination and an alternative theory. Am J Psychol. 1927;39(1/4):106-24.

Cannon WB. Again the james-lange and the thalamic theories of emotion. Psychol Rev. 1931;38(4):281-95.

Canteras NS. Análise crítica dos sistemas neurais envolvidos nas respostas de medo inato. Rev Bras Psiquiatr. 2003:25(Supl 2):21-4.

Chittka l, Niven J. Are Bigger Brains Better? Curr Biol. 2009;19(21):R995-1008.

Colaço B, Ferreira D, Gonzalo-Ordén M, Lacilla JMV. A aplicação da ressonância magnética no estudo anatômico do encéfalo de cães. Ver Port Cienc Vet. 2003;98(548):159-65.

Cosenza RM. Fundamentos de Neuroanatomia. Rio de Janeiro: Guanabara Koogan; 2012. 156 p.

Damasio A, Carvalho GB. The nature of feelings: evolutionary and neurobiological origins. Nat Rev Neurosci. 2013;14:143-52. 
Davis M. The role of the amygdala in fear and anxiety. Annu Rev Neurosci. 1992;15:353-75.

Deak A. Brain and emotion: Cognitive neuroscience of emotions. Rev Psychol. 2011;18(2)71-80. Disponível em: https://tinyurl.com/y7twd8jv.

Esperidião-Antonio V, Majeski-Colombo M, ToledoMonteverde D, Moraes-Martins G, Fernandes JJ, Assis $\mathrm{MB}$, et al. Neurobiologia das emoções. Ver Psiq Clin. 2008;35(2):55-65.

Foa EB, Kozak MJ. Emotional Processing of fear: exposure to corrective information. Psychol Bull. 1986;99(1): 20-35.

Gazzaniga MS, Ivry RB, Mangun GR. Neurociência cognitiva: a biologia da mente. Porto Alegre: Artmed; 2006. 767 p.

Goleman D. Inteligência emocional. Rio de Janeiro: Objetiva; 2011.

Graeff FG. Ansiedade, pânico e o eixo hipotálamopituitária-adrenal. Rev Bras Psiquiatr. 2007;29(Supl 1):S3-6.

Guyton AC, Hall JE. Tratado de fisiologia médica. 13 ed. Rio de Janeiro: Elsevier; 2017. 1168 p.

Haug H. Brain sizes, surfaces, and neuronal sizes of the cortex cerebri: a stereologi-cal investigation of man and his variability and a comparison with some mammals (primates, whales, marsupials, insectivores, and one elephant). Am J Anat. 1987;180(2):126-42.

Hendelman WJ. Atlas of Functional Neuroanatomy. Boca Raton, FL: CRC Press; 2006. 325 p.

Herrmann KA, Broihier HT. What neurons tell themselves: autocrine signals play essential roles in neuronal develop-ment and function. Curr Opin Neurobiol. 2018;51:70-9.

JamesW.Whatis an emotion? Mind.1884;9(34):188-205.

Kalin NH. The neurobiology of fear. Sci Am. 2002;286(4): 72-81.
Kandel ER, Schwartz JH, Jessell TM. Fundamentos da neurociência e do comportamento. Rio de Janeiro: Guanabara-Koogan; 1997. 591 p.

Kass JH. The evolution of brains from early mammals to humans. Wiley Interdiscip Rev Cogn Sci. 2013;4(1):33-45.

Kim JJ, Rison RA, Fanselow MS. Effects of amygdala, hippocampus, and periaqueductal gray lesions on short- and long-term contextual fear. Behav Neurosci. 1993;107(6):1093-8.

Kolb B, Whishaw IQ. Neurociência do comportamento. Barueri: Manole; 2002.601 p.

König HE, Liebich HG, Cerveny C. Sistema Nervoso. In: König HE, Liebich HG (EE.). Anatomia dos Animais Domésticos - Texto e atlas colorido. Porto Alegre: Artmed; 2004. p. 203-75.

Lange CG, James W. Emotions. Baltimore: Williams \& Wilkins Company; 1922. 145 p.

LeDoux JE. Emotion, memory and the brain. Sci Am. 2002;286(4):62-71.

LeDoux JE. The emotional brain, fear, and the amygdala. Cell Mol Neurobiol. 2003;23(4-5):727-38.

LeDoux JE, Iwata J, Cicchetti P, Reis DJ. Different projections of the central amygdaloid nucleus mediate autonomic and behavioral correlates of conditioned fear. J Neurosci. 1988;8(7):2517-29.

LentR.Cembilhões de neurônios? Conceitos fundamentais de neurociência. São Paulo: Atheneu; 2010. 786 p.

Machado ABM. Neuroanatomia funcional. São Paulo: Atheneu; 2006. 363 p.

Macrì S, Pasquali $\mathrm{P}$, Bonsignore LT, Pieretti S, Cirulli F, Chiarotti $\mathrm{F}$, et al. Moderate neonatal stress decreases within-group variation in behavioral, immune and HPA responses in adult mice. Plos One 2007;2(10):e1015.

Marcondes M. Sistema Nervoso. In: Feitosa FLF (E.). Semiologia Veterinária - A arte do diagnóstico. São Paulo: Roca; 2008. p. 411-95. 
Martin JH. Neuroanatomia - Texto e atlas. Porto Alegre: Artmed, 2013. p. 385-413.

Meneses MS. Neuroanatomia aplicada. Rio de Janeiro: Guanabara Koogan; 2011. 368 p.

Mezzasalma MA, Valença AM, Lopes FL, Nascimento I, Zin WA, Nardi AE. Neuroanatomia do transtorno de pânico. Rev Bras Psiquiatr. 2004;26(3):202-6.

Nelson RW, Couto CG. Medicina interna de pequenos animais. 5 ed. Rio de Janeiro: Elsevier; 2015. 1512 p.

Neuroscience Library [acesso 30 jan 2018]. Disponível em: https://tinyurl.com/ybx95bsb.

Oliveira MAD. Neurofisiologia do comportamento - Uma relação entre o funcionamento cerebral e as manifestações comportamentais. Canoas: ULBRA; 2000.

Panksepp J, Fuchs T, Iacobucci P. The basic neuroscience of emotional experiences in mammals: The case of subcortical FEAR circuitry and implications for clinical anx-iety. Appl Anim Behav Sci. 2011;129(1):1-17.

Papez JW. A proposed mechanism of emotion. Arch Neurol Psychiatry. 1937;38(4): 725-43.

Pawlowski J, Rosa HLRS, Fonseca JM, Silva RB, Ambrósio EG, Souza GMB. Avali-ação da memória de pacientes com lesão em núcleos de base e tálamo pós-AVC. Psicol Pesq. 2013;7(1):79-88.

Pinel JPJ. Biopsicologia. Porto Alegre: Artmed; 2005. 576 p.
Prada I. Neuroanatomia funcional em medicina veterinária com correlações clínicas. Jaboticabal: Terra Molhada; 2014.616 p.

Purves D. Neurociências. 2 ed. Porto Alegre: Artmed; 2005.

Romero SMB. Fundamentos de Neurofisiologia Comparada. Da recepção à integração. Ribeirão Preto: Holos; 2000. 170 p.

Rosen JB, Pagani JH, Rolla KLG, Davis C. Analysis of behavioral constraints and the neuroanatomy of fear to the predator odor trimethylthiazoline: A model for animal phobias. Neurosci Biobehav Rev. 2008;32(7): 1267-76.

Sánchez-Ramírez JD, Uribe-Velásquez LF. Aspectos neurobiológicos implicados en el miedo animal. Biosalud. 2009;8(1):189-213.

Schmidt RF. Neurofisiologia. São Paulo: EPU (Editora Pedagógica e Universitária);1979. 372 p.

Teillery JC. Antropología simbólica de las emociones y neurociencia. Alteridades. 2017;27(53):23-33.

Viana DML, Brandão ML. Anatomical connections of the periaqueductal gray: specific neural substrates for different kinds of fear. Braz J Med Biol Res. 2003;36(5):557-66.

Zacharias M, Zacharias E. Dicionário de medicina legal. Curitiba: Universitária Champagnat; 1991.411 p. 